\title{
The expression of secreted aspartyl proteinases of Candida species in human whole saliva
}

\author{
T. WU* and L. P. SAMARANAYAKE \\ Oral Bio-science Laboratories, Faculty of Dentistry, University of Hong Kong, Hong Kong
}

\begin{abstract}
The expression of secreted aspartyl proteinases (Saps) by clinical isolates of Candida albicans, $C$. tropicalis and $C$. parapsilosis in human saliva supplemented with glucose and in a proteinase-inducing medium (YCB-BSA), was investigated. Also, yeast growth, pH fluctuation and total protein concentration of the saliva cultures during incubation were measured. Sap expression was assessed by evaluating the enzyme activity as well as the antigen concentration. Saps were expressed well in human saliva supplemented with glucose by all three Candida species, although greater expressions was found in YCBBSA medium. $C$. albicans isolates were significantly more proteolytic than the nonalbicans isolates. In general, for all three species, the rate of yeast growth, pH fluctuation and percentage reduction of total salivary protein concentration concurred with the degree of expression of Saps. These data strongly suggest that Saps of $C$. albicans, $C$. tropicalis and $C$. parapsilosis may play an active role in the progression of oral candidoses, particularly with regard to the abundance of low pH microenvironments in the oral cavity, which are regularly replenished with dietary carbohydrates.
\end{abstract}

\section{Introduction}

Candida spp. - of which C. albicans is of foremost medical importance, followed by $C$. tropicalis and $C$. parapsilosis - are notorious opportunist pathogens that cause a variety of oral infections. These three species are distinguished from other Candida spp. by their ability to secrete aspartyl proteinase in vitro [1,2]. Ruchel et al. [3] and Odds [4] studied the ability of different Candida spp. to produce secreted aspartyl proteinases (Saps) and reported variable activity among different Candida spp.; e.g., $C$. tropicalis and $C$. parapsilosis produce less proteinase (Sapt and Sapp, respectively) than $C$. albicans. These proteinases are routinely expressed in vitro in candidal cultures containing high mol.wt nitrogen sources, such as bovine serum albumin (BSA), at around $\mathrm{pH} 5.0$ [4]. The Saps appear to correlate well with virulence, as

Recieved 24 March 1998; revised version accepted 26 Oct. 1998.

Corresponding author: Professor L. P. Samaranayake (e-mail: lakshman@hkucc.hku.hk).

*Present address: Division of Bacterial and Mycotic Disease, Centers for Disease Control and Prevention, Atlanta, GA 30333, USA. proteolytic wild-type strains of $C$. albicans cause more extensive infection in mice than Sap-deficient mutants [5]. Others have also found correlations between proteinase activity and virulence $[6,7]$.

Nine iso-enzymes are expressed by different $C$. albicans strains [8], with Sap2 being the most abundant; it has an $\mathrm{M}_{\mathrm{r}}$ in the range $43-45 \mathrm{kDa}$ [9]. The optimal $\mathrm{pH}$ for $S A P 2$ gene expression is 4.4 and it can be denatured irreversibly above $\mathrm{pH} 8.0$ [10]. Two iso-enzymes of Sapt have been verified so far [11]; they are $43-\mathrm{kDa}$ glycoproteins with $\mathrm{pH}$ optima between 3.4 and 3.8, and a pI of 4.5 [12]. Two isoforms of Sapp have been confirmed, Sapp1 and Sapp2 [11]; they are distinguished by a lower $\mathrm{M}_{\mathrm{r}}$ of $33 \mathrm{kDa}$ and a higher $\mathrm{pI}$ of $5.7[12,13]$. Immunological studies suggest the existence of common and specific antigenic domains among the aspartyl proteinases of the three species [4].

Although considerable evidence indicates that Saps are potential virulence factors of $C$. albicans, $C$. tropicalis and $C$. parapsilosis, there is little information on their expression and activity in biological fluids such as saliva. Saliva contains antimicrobial proteins including immunoglobulins, lysozyme (muramidase), lactoferrin and the peroxidase system [14]. Lactoferrin and peroxidase are likely to be degraded proteolytically in the 
same manner as the secreted immunoglobulins by proteinases of Candida spp., although lysozyme is resistant due to its basic iso-electric point and high charge [5]. The attenuation of $C$. albicans Sap production by sublethal concentrations of lysozyme (unpublished observations) indicates that the Sap activity may be modulated by salivary constituents in vivo. As oral yeasts reside in a milieu bathed in this fluid medium, it is important to verify the extent to which candidal Saps are active in saliva and the salivary factors, if any, that may modify this phenomenon.

Germaine and Tellefson [15] were the first to report the growth of $C$. albicans in vitro under acidic conditions and its degradation of salivary proteins. They observed marked proteolysis at $\mathrm{pH} 4.0$, less at $\mathrm{pH} 5.0$, and a complete lack of proteolysis at $\mathrm{pH} 6.0$ and 7.0. However, they also found that saliva inhibited candidal Sap synthesis and concluded that the enzymes did not contribute to virulence in vivo [15]. These observations contradict those of Samaranayake et al. [16,17], who demonstrated the growth of $C$. albicans in human mixed saliva and concomitant salivary proteolysis. As only $C$. albicans and $C$. tropicalis isolates were used in these studies, there is no information available on the expression of Sapp by $C$. parapsilosis in salivary cultures.

The aim of the present investigation was to study aspartyl poteinase expression by three Candida spp. in human mixed saliva supplemented with glucose. The study entailed examination of growth, and the enzyme activity and antigen concentrations of the proteinases by spectrophotometry, enzyme-linked immunosorbent assay (ELISA) and immunoblotting (Western blotting). $\mathrm{pH}$ fluctuations and total protein concentrations during incubation of the saliva-yeast cultures were also monitored.

\section{Materials and methods}

\section{Organisms}

Nine oral Candida isolates were investigated; these were proteinase positive and belonged to three species - C. albicans (three isolates), C. tropicalis (three) and $C$. parapsilosis (three). The $C$. albicans isolates BM20617, BS742 and BU1010) were from HIVinfected individuals in Hong Kong attending the Oral AIDS Research Clinic, Faculty of Dentistry, Hong Kong. Two isolates each of C. tropicalis (T155700 and $\mathrm{T} 155646)$ and $C$. parapsilosis (P154538(1) and P134023K(2)) were from healthy individuals in Hong Kong. C. tropicalis $003 \mathrm{~T}$ and C. parapsilosis N6 were from healthy individuals from Tanzania and Norway, respectively. All isolates were derived from oral rinse or swab samples of individuals without signs or symptoms of oral candidosis. The yeasts were identified with API 20C test kits (API Laboratory Products, Basingstoke) and by the germ-tube test [18].

\section{Saliva preparation}

Unstimulated whole saliva was collected from a healthy young individual by expectoration into a universal container held over ice. Samples were always collected between 10.00 and $12.00 \mathrm{am}$, then pooled and centrifuged at $10000 \mathrm{rpm}$ for $20 \mathrm{~min}$ at $4^{\circ} \mathrm{C}$. The supernate was then filtered through a $2.0-\mu \mathrm{m}$ pore membrane filter (Corning Glass Works, Corning, NY, USA). To ascertain the sterility of the supernate, $0.05 \mathrm{ml}$ of streptomycin-penicillin solution $(10000 \mu \mathrm{g} / \mathrm{ml}$ and $10000 \mathrm{U} / \mathrm{ml}$, respectively; Gibco Laboratories, Paisley) was added to $10-\mathrm{ml}$ samples of supernate, and they were immediately stored at $-20^{\circ} \mathrm{C}$. The frozen samples were used within $24 \mathrm{~h}$.

Before each experiment, saliva was supplemented by adding sterile $1 \mathrm{M}$ glucose solution to yield a final concentration of $200 \mathrm{mM}$ glucose. The sterility of the saliva samples was checked routinely by culture on blood agar and Sabouraud's Dextrose Agar (Gibco Laboratories), before each assay.

\section{Growth and proteinase production}

The isolates were grown aerobically on Sabouraud's dextrose agar at $37^{\circ} \mathrm{C}$ for $24 \mathrm{~h}$. One loopful of the resultant culture was pre-cultured in YCB-BSA medium - yeast carbon base $23.4 \mathrm{~g}$, yeast extract $2.0 \mathrm{~g}$ (Difco, Detroit, MI, USA) and bovine serum albumin $4.0 \mathrm{~g} / \mathrm{L}$ (Sigma) adjusted to $\mathrm{pH} 5$ and filter-sterilised which induces proteinase expression [19], in an orbital incubator at $37^{\circ} \mathrm{C}$ for $24 \mathrm{~h}$. The cells were harvested (5000 rpm for $10 \mathrm{~min}$ ) and washed twice with sterile saline, transferred into the prepared saliva and the initial inoculum was adjusted to $1 \times 10^{6}$ cells $/ \mathrm{ml}$ with a haemocytometer. Then the saliva candida suspension was incubated with agitation $(150 \mathrm{rpm})$ at $37^{\circ} \mathrm{C}$, for $72 \mathrm{~h}$ in an orbital shaker. Samples were removed at 12$\mathrm{h}$ intervals and assayed for cell growth, $\mathrm{pH}$ value, protein concentration and Sap level. Growth was determined by the assessment of $\mathrm{cfu} / \mathrm{ml}$ of the sample on Sabouraud's dextrose agar. Growth assays were conducted concurrently in YCB-BSA medium for comparison with the saliva cultures. In this experiment, one isolate from each Candida sp. was used, i.e., $C$. albicans BM20617, C. tropicalis 003T and C. parapsilosis P154538(1).

\section{Measurement of $\mathrm{pH}$ value}

The $\mathrm{pH}$ value of the saliva cultures during incubation for $72 \mathrm{~h}$ was measured with a $\mathrm{pH}$ meter (Sentron instruments, Model 501, The Netherlands). The $\mathrm{pH}$ meter was calibrated before use at two $\mathrm{pH}$ levels $\mathrm{pH}$ 7.0 and $\mathrm{pH} 4.0$ ), with standard buffers.

\section{Assessment of protein concentration of the saliva culture}

The protein concentration of the saliva cultures was determined by the Coomassie Blue assay [20]. Samples 
$(80 \mu \mathrm{l})$ of saliva culture were applied to each well of a micro-test plate (Dynatech Microelisa, CA, USA) with dye reagent (BioRad Laboratories, USA) $20 \mu 1$ and mixed thoroughly. The final reading was obtained by measuring the $\mathrm{OD}_{595}$ in an automated microreader (BioRad). The protein concentration of the samples was calculated from a standard curve obtained by plotting the $\mathrm{OD}_{595}$ of standard BSA solutions (Sigma) at a range of $200-14000 \mu \mathrm{g} / \mathrm{ml}$ (each $0.1 \mu \mathrm{l}$ of BSA solution was mixed with $50 \mu \mathrm{l}$ of the dye reagent to conduct the standard assay).

\section{Assessment of proteinase activity}

Two methods, spectrophotometric assay [21] and ELISA [22], were used to evaluate the proteinase expression of three Candida spp. in whole saliva and YCB-BSA medium. For spectrophotometry, each assay included $0.1 \mathrm{ml}$ of culture supernate and $0.4 \mathrm{ml}$ of $0.1 \mathrm{M}$ citrate buffer ( $\mathrm{pH} 3.2$ ) containing BSA $1 \%$. The control consisted of identical ingredients and pepstatin A (Sigma) $50.0 \mu \mathrm{g} / \mathrm{ml}$ which acted as the proteinase inhibitor. After incubation at $37^{\circ} \mathrm{C}$ for $15 \mathrm{~min}$, the reaction was stopped with trichloroacetic acid (TCA) $5 \%$ on ice, the mixture was centrifuged, the absorbance of the supernate was read at $280 \mathrm{~nm}$ against a blank containing distilled water. One unit of enzyme activity was expressed as the amount, in micromoles, of tyrosine equivalents released $/ \mathrm{min} / \mathrm{ml}$ of culture supernate [8].

Proteinase antigen concentration was also assessed by ELISA. For this, the antisera against $C$. albicans [22] and C. tropicalis [12] Saps were raised in rabbits; the antiserum against Sapp was derived from guinea-pig [13]. The antisera against Sap2 and the purified Sap2 were kind gifts from Professor P. A. Sullivan (New Zealand). The antisera against Sapt and Sapp and the purified Sapt and Sapp were from Professor R. Ruchel (Germany). Dilution of the proteinase antiserum used was 1 in 5000 for C. tropicalis and C. parapsilosis and 1 in 500 for $C$. albicans. The secondary antibodies for $C$. albicans and $C$. tropicalis were phosphatase-conjugated goat anti-rabbit IgG (Sigma) and for $C$. parapsilosis phosphatase-conjugated goat anti-guinea-pig IgG (Sig$\mathrm{ma}) ;$ these were used at a dilution of 1 in 1000 .

First, $100-\mu 1$ samples of the culture supernate were mixed with $0.5 \mathrm{ml}$ of TCA $50 \%(\mathrm{w} / \mathrm{v})$, incubated for $30 \mathrm{~min}$ on ice and centrifuged at $10000 \mathrm{rpm}$ for $10 \mathrm{~min}$; the pellets were washed twice with ethanol $95 \%$, dissolved in SDS $1 \%$, boiled for 3 min, diluted in $0.2 \mathrm{M}$ sodium carbonate buffer, $\mathrm{pH} 9.5$, and applied $(70 \mu \mathrm{l})$ to the micro-test plates (Dynatech Microelisa). The plates were incubated overnight at $4^{\circ} \mathrm{C}$, rinsed three times with phosphate-buffered saline (PBS, $0.1 \mathrm{M}$, pH 7.4) containing Tween $200.05 \% \mathrm{v} / \mathrm{v}$ and blocked with BSA $1 \%$ PBS buffer for $1 \mathrm{~h}$ at $37^{\circ} \mathrm{C}$. Antiproteinase serum $(100 \mu \mathrm{l})$ was added at various dilutions in PBS and incubated for $2 \mathrm{~h}$ at $37^{\circ} \mathrm{C}$. After washing, $100 \mu \mathrm{l}$ diluted secondary antibody were added and incubated for $2 \mathrm{~h}$ at $37^{\circ} \mathrm{C}$. Finally, the reaction was detected with $p$-nitrophenyl phosphate (Sigma) and terminated by adding $20 \mu \mathrm{l}$ of $3 \mathrm{M} \mathrm{NaOH}$ after $20 \mathrm{~min}$. The plates were read with an automated microreader (BioRad) at $405 \mathrm{~nm}$, blanked against air. The amounts of proteinase were calculated from a standard curve (1-110 ng) determined with purified Sap as coating antigen under the conditions described above. Reaction controls included negative tests without coating antigen or antibodies.

\section{Western blotting}

Western blotting was performed as follows. Supernates from fresh YCB-BSA and saliva culture were collected after incubation for $36 \mathrm{~h}$. SDS-PAGE of proteins was performed in vertical slab acrylamide $10 \% \mathrm{w} / \mathrm{v}$ gels (BioRad). Proteins were transferred electrophoretically from polyacrylamide gels to nitrocellulose membranes with the semi-dry electrophoretic transfer cell (BioRad) for $1 \mathrm{~h}$ at $15 \mathrm{~V}$ and $180 \mathrm{~mA}$. After complete transfer, as verified by a silver staining, the membrane was incubated with BSA $3 \%$ in Tris-buffered saline (TBS, $\mathrm{pH}$ 7.6) for $1 \mathrm{~h}$ at $37^{\circ} \mathrm{C}$, and then in proteinase (Sap, Sapt and Sapp) antiserum (diluted 1 in 200) in BSA $1 \%$ TBS for $2 \mathrm{~h}$ at $37^{\circ} \mathrm{C}$, with gentle agitation. The membrane was rinsed twice for $10 \mathrm{~min}$ with Tween 20 $0.05 \%$ in Tris-buffered saline (TABS), then once briefly with distilled water, and incubated with the second antibody. The second antibodies for C. albicans and $C$. tropicalis were goat anti-rabbit IgG-peroxidase conjugate (Sigma); for C. parapsilosis the second antibody was goat anti-guinea-pig IgG-alkaline phosphatase conjugate (Sigma). The dilution of the three antibodies was 1 in 500 in BSA $1 \%$ TBS. After rinsing in TABS twice for $10 \mathrm{~min}$, then once in distilled water, the membrane was exposed to the substrates. Chromogenic diaminobenzidine (Sigma) was used as the substrate for C. albicans and C. tropicalis; 5-bromo-4-chloro-3indolyl phosphate/nitro blue tetrazolium (BCIP/NBT) (Sigma) was used as the substrate for $C$. parapsilosis.

In the yeast growth experiments, a selected isolate from each species (three isolates in total) was grown in saliva on a single occasion, whereas in $\mathrm{pH}$ studies, a total of three isolates from each of the three Candida species (nine isolates) was used.

\section{Results}

Yeast growth in whole saliva and YCB-BSA medium

Data on the growth of $C$. albicans BM20617, $C$. tropicalis 003T and C. parapsilosis 154538(1) in whole saliva and YCB-BSA medium are presented in Fig. 1. All the isolates grew well in whole saliva, but $C$. albicans demonstrated more rapid and abundant growth than the other two species. C. albicans 


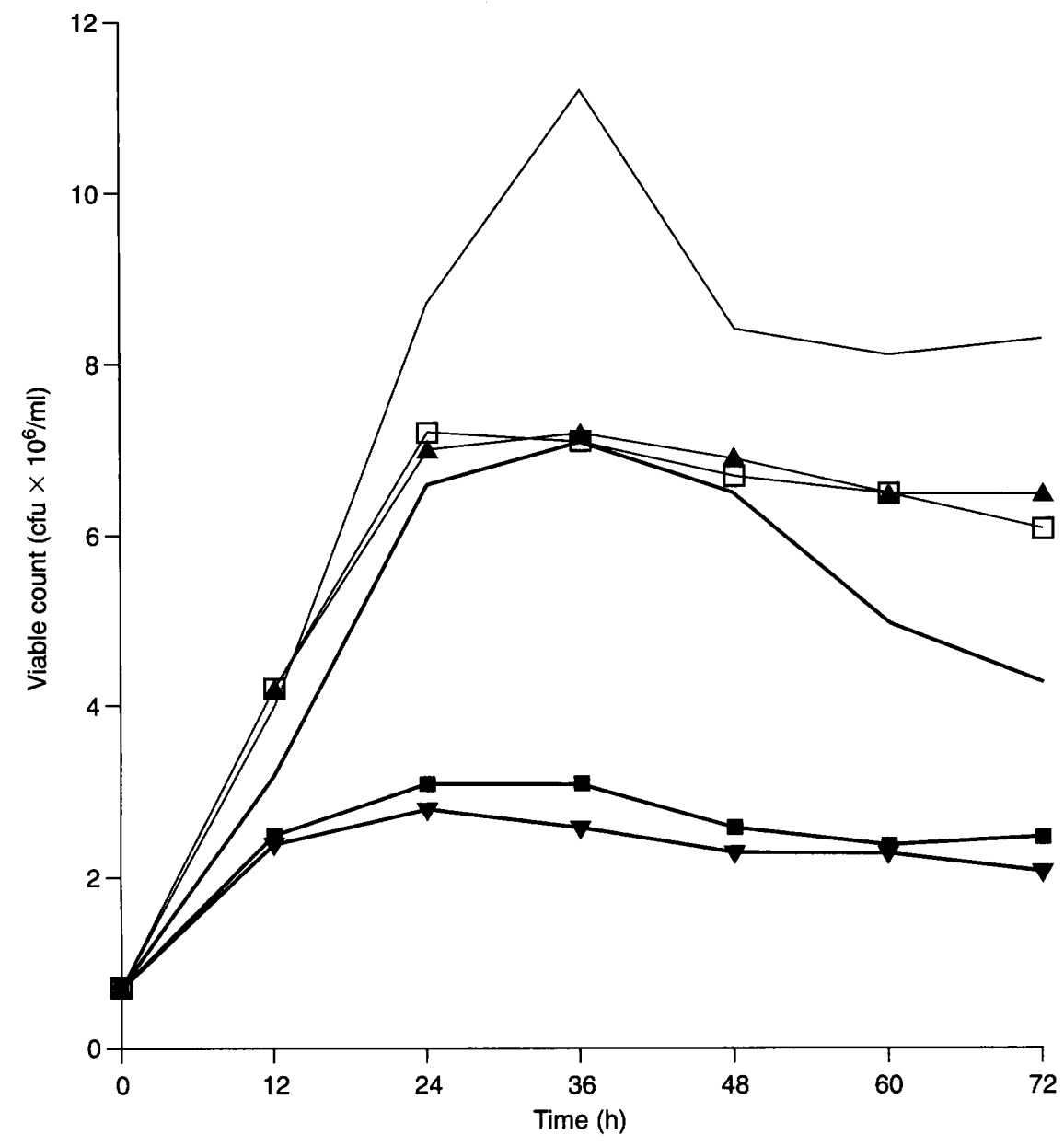

Fig. 1. Growth curves of C. albicans BM20617 (-, -), C. parapsilosis 154538(1) $(\square$, $\square)$ and C. tropicalis 003T $(\boldsymbol{\Lambda}, \boldsymbol{\nabla})$ isolates in human whole saliva $(\boldsymbol{-}, \boldsymbol{\square}, \boldsymbol{\nabla})$ and YCB-BSA medium $(-, \square, \boldsymbol{\Delta})$.

BM20617 took $36 \mathrm{~h}$ to reach the stationary phase of growth (when the cell concentration was $7.1 \times$ $10^{6} \mathrm{cfu} / \mathrm{ml}$ ), whereas $C$. tropicalis $003 \mathrm{~T}$ and $C$. parapsilosis $154538(1)$ reached a stationary phase after c. $24 \mathrm{~h}$ (when the cell concentration was $2.8 \times 10^{6}$ $\mathrm{cfu} / \mathrm{ml}$ and $3.1 \times 10^{6} \mathrm{cfu} / \mathrm{ml}$, respectively).

The three Candida isolates grew better during incubation for $72 \mathrm{~h}$ in YCB-BSA medium than in saliva (Fig. 1). No significant difference was observed between the growth of $C$. parapsilosis 154838(1) and C. tropicalis $003 \mathrm{~T}$ in saliva or YCB-BSA medium.

\section{pH profiles of saliva cultures}

The $\mathrm{pH}$ curves of the saliva cultures of the three Candida spp. during the $72-\mathrm{h}$ incubation period are shown in Fig. 2. The pH fell slightly immediately after the addition of the Candida isolates in all saliva cultures. In the cultures of $C$. albicans isolates BM20617, BU1010 and BS742, the $\mathrm{pH}$ fell (from 7.9) to $2.7,2.9$ and 3.0 respectively, over a period of $36 \mathrm{~h}$. The $\mathrm{pH}$ fall induced by both $C$. tropicalis and $C$. parapsilosis was less than that of $C$. albicans; the lowest $\mathrm{pH}$ induced by $C$. albicans was 2.7 , while the equivalent value was 5.4 for $C$. parapsilosis and 4.9 for
C. tropicalis. Also, the $\mathrm{pH}$ decrease induced by $C$. tropicalis during incubation for $72 \mathrm{~h}$ was not significantly different from that induced by $C$. parapsilosis.

\section{Proteinase activity of Candida spp. in saliva cultures}

Proteinase activity was expressed by all three Candida spp. during the 72-h incubation period in YCB-BSA medium and whole saliva. In general, with all three species, the proteinase activity peaked at c. $36 \mathrm{~h}$ of fungal growth and declined thereafter (Fig. 3). Furthermore, proteinase activity was consistently lower in saliva cultures than in YCB-BSA medium for all species. However, the proteinase activity of $C$. albicans in saliva culture was still higher than that of $C$. parapsilosis and C. tropicalis (Fig. 3); a similar pattern was observed in YCB-BSA medium. There was no significant difference between the proteinase activity of C. parapsilosis and C. tropicalis.

\section{Proteinase antigen concentration of Candida spp.} in saliva cultures

In addition to spectrophotometric assessment of the proteinnase activity reported above, the proteinase 


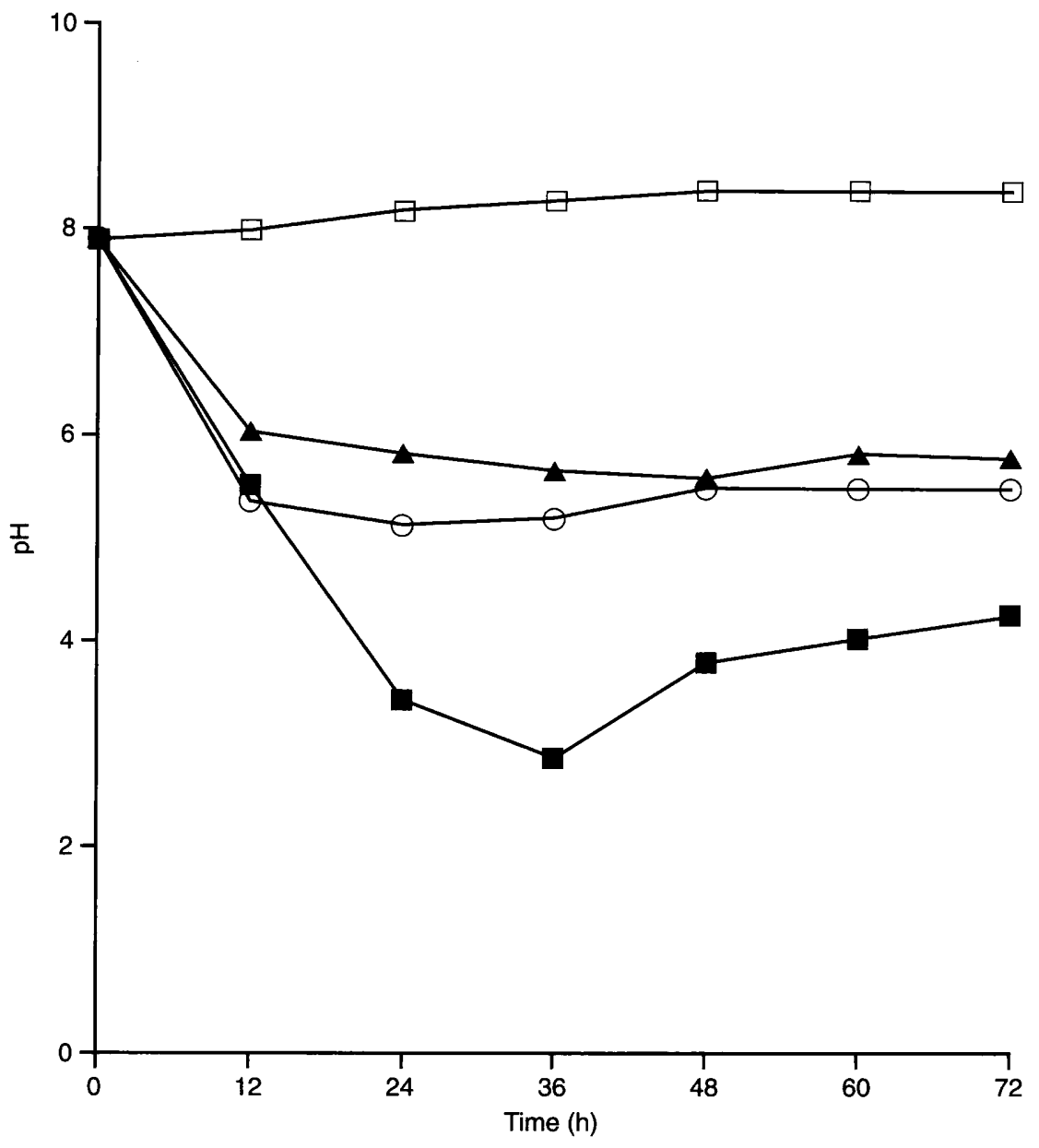

Fig. 2. $\mathrm{pH}$ curves of the saliva culture medium during the $72-\mathrm{h}$ incubation period with three isolates each of C. albicans $(\mathbf{\square})$, C. parapsilosis $(\mathbf{\Delta})$ and C. tropicalis $(\mathrm{O})$ and an uninoculated control saliva sample $(\square)$.

antigen concentration of the Candida isolates was evaluated by ELISA. In general, proteinase concentration of all nine Candida isolates, belonging to three different species, peaked at $c .48 \mathrm{~h}$ in both whole saliva and YCB-BSA medium and declined thereafter (Fig. 4). The proteinase concentration of the Candida isolates was consistently lower in whole saliva than in YCB-BSA medium. Enzyme production by $C$. albicans was significantly higher than that of $C$. parapsilosis and $C$. tropicalis isolates; there was no significant difference between $C$. parapsilosis and $C$. tropicalis isolates.

\section{Western blotting}

Western blotting was performed to confirm the identity of the antigens detected by ELISA (Fig. 5). Probing whole saliva culture supernates $(36 \mathrm{~h})$ of $C$. albicans BM20617, C. tropicalis $003 \mathrm{~T}$ and $C$. parapsilosis $154538(1)$ with the antiserum of each species revealed positive bands of $43 \mathrm{kDa}$ in the case of $C$. albicans and C. tropicalis, and $33 \mathrm{kDa}$ in the case of C. parapsilosis. Protein bands with identical molecular sizes were also obtained from YCB-BSA culture supernates of all three Candida spp. (Fig. 5). These bands derived from
Candida saliva/YCB-BSA cultures were of the same molecular size as the purified proteinase of each species obtained from external sources.

\section{Percentage reduction in salivary total protein concentration}

When the percentage reduction in salivary proteins was compared, C. albicans, in general, produced the largest reduction in salivary proteins compared with the other two species (Fig. 6). On the other hand, the proteolytic activity of $C$. parapsilosis and $C$. tropicalis isolates was similar (Fig. 6). In quantitative terms, after incubation for $72 \mathrm{~h}$, the mean percentage reduction of salivary proteins by the three $C$. albicans isolates was $62.7 \%$; C. parapsilosis and $C$. tropicalis isolates produced $42.2 \%$ and $49.3 \%$ reduction, respectively.

\section{Discussion}

These results demonstrate clearly that isolates of $C$. albicans, $C$. parapsilosis and $C$. tropicalis have the ability to grow well in whole saliva supplemented with glucose, although less profusely than in the YCB-BSA 
a

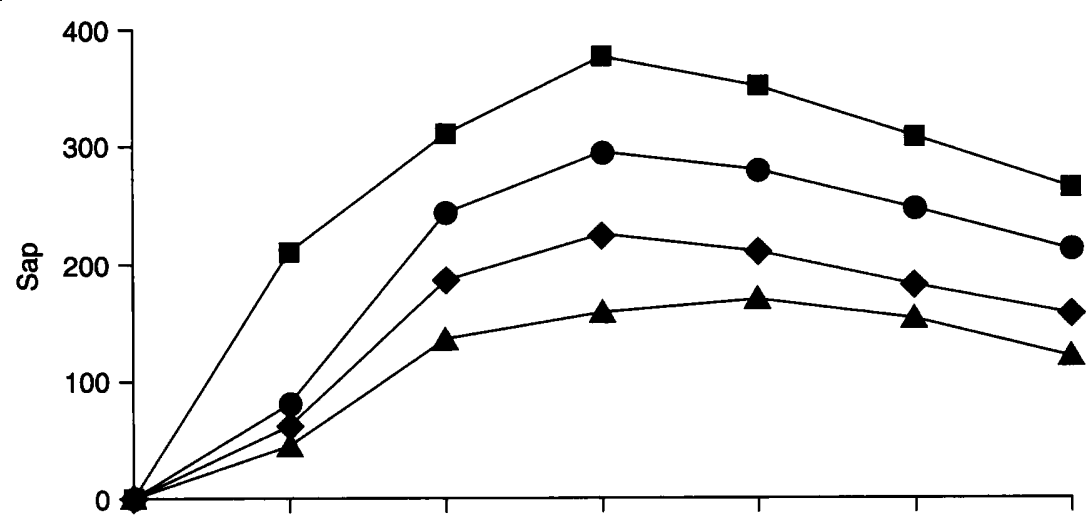

b
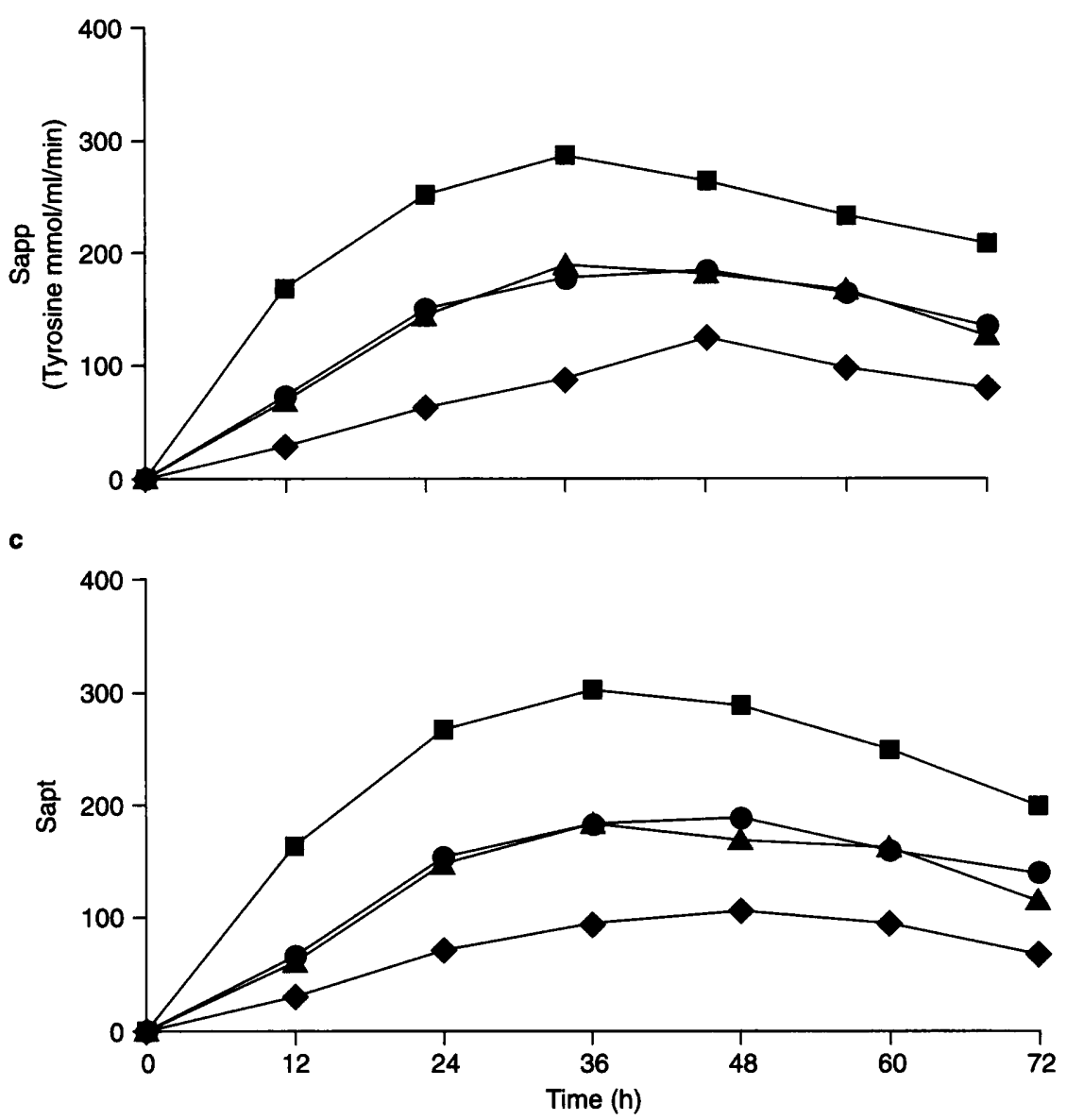

Fig. 3. Secreted aspartyl proteinase activity measured by spectrophotometry of (a) C. albicans BM20617 ( $\mathbf{\square}, 0)$,

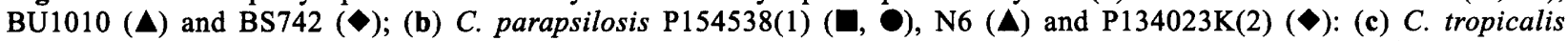
$003 \mathrm{~T}(\boldsymbol{\square}, \boldsymbol{\ominus}), \mathrm{T} 155700(\boldsymbol{\Delta})$ and T155646 $(\diamond)$ during incubation for $72 \mathrm{~h}$ in human whole saliva $(\bullet, \boldsymbol{\Delta}, \diamond)$ and $\mathrm{YCB}-$ BSA medium ( $\boldsymbol{\square})$.

medium. Although only results from a single representative isolate from each species are shown (Fig. 1), all isolates demonstrated the same trend. Whilst the growth of $C$. albicans and C. tropicalis in human saliva culture has been reported by Samaranayake et al. [17], this is the first study demonstrating $C$. parapsilosis growth in human saliva in vitro. These results together with previous work $[17,23]$ convincingly demonstrate the ability of yeasts to grow in saliva while expressing their extracellular proteolytic activity. The latter phenomenon, in particular, has been questioned by
Germaine and Tellefson [15], who studied only a single $C$. albicans isolate, and the current data refute their contention.

A marked fall in $\mathrm{pH}$ was detected in human mixed saliva candida cultures, especially for $C$. albicans and it is likely that this is due to the acidogenic nature of C. albicans compared with the other two species. Although the acidogenic and aciduric nature of $C$. albicans and $C$. tropicalis cultured in glucose-supplemented media has been reported by others $[16,17$, 
a

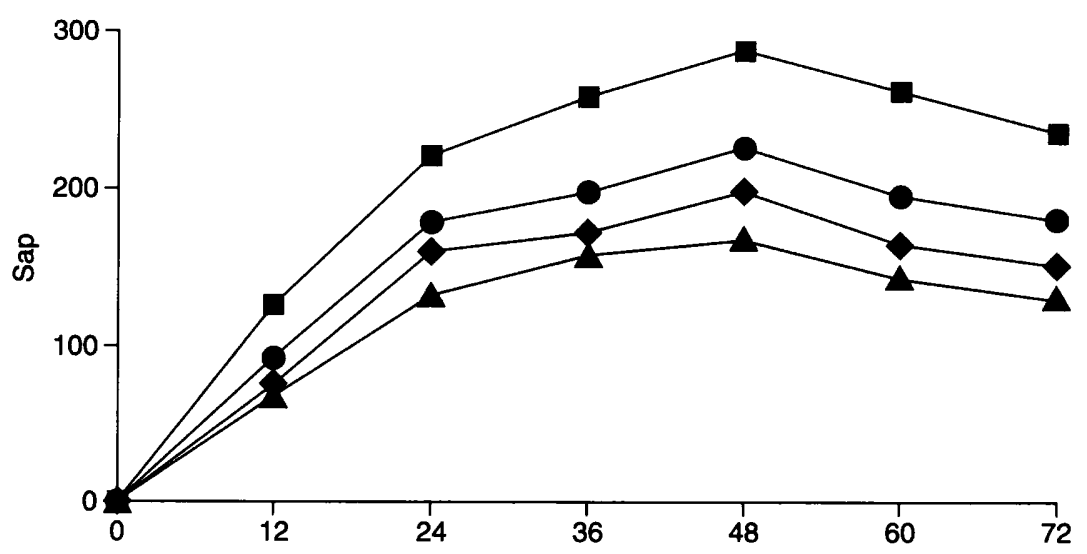

b

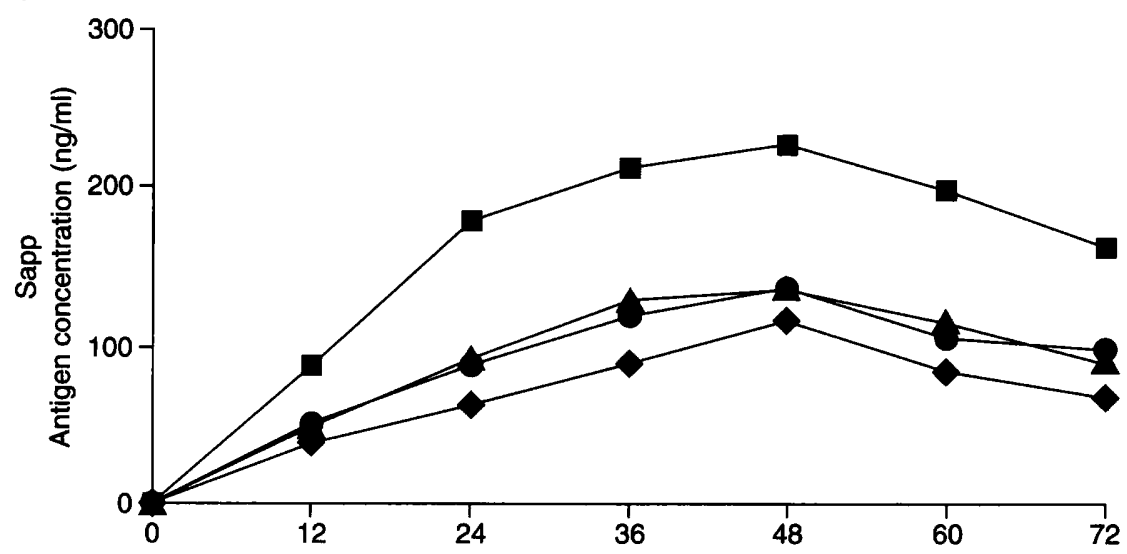

c

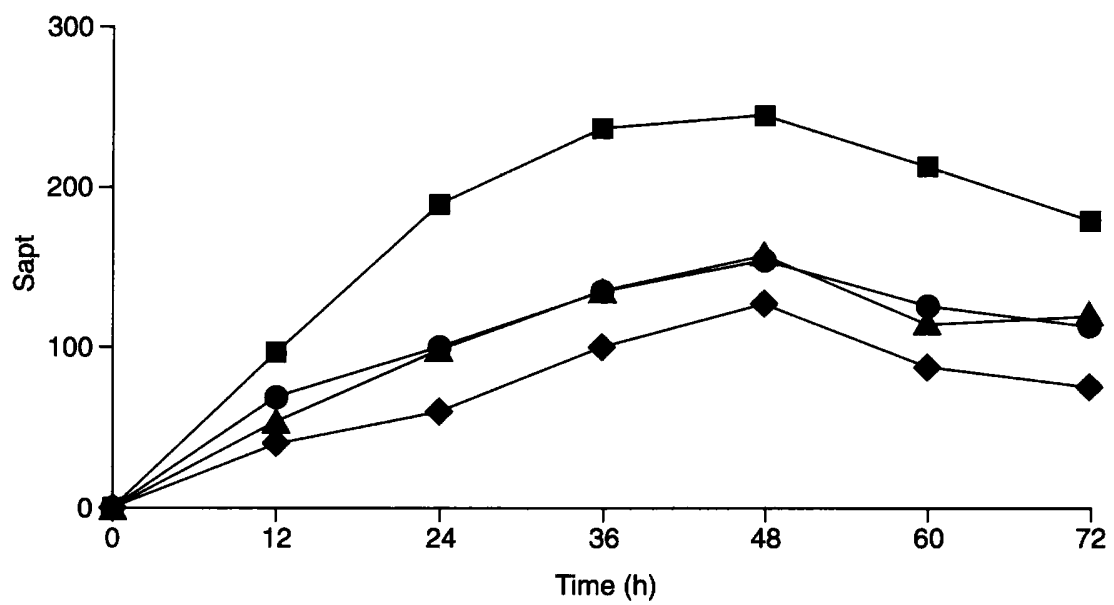

Fig. 4. Secreted aspartyl proteinase antigen concentration assessed by ELISA in (a) C. albicans BM20617 ( $\square$, ๑),

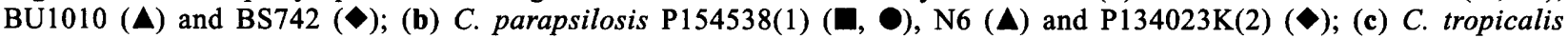
003T $(\boldsymbol{\Sigma}, \boldsymbol{\bullet})$, T155700 $(\boldsymbol{\Delta})$ and T155646 $(\diamond)$ during incubation for $72 \mathrm{~h}$ in human whole saliva $(\boldsymbol{\bullet}, \boldsymbol{\Delta}, \diamond)$ and YCBBSA medium ( $\mathbf{\square})$.

24, 25], the current results highlight these properties for $C$. parapsilosis. In general, $\mathrm{pH}$ minima were reached with all nine isolates at $c .36 \mathrm{~h}$, after which an increased $\mathrm{pH}$ was detected - particularly in $C$. albicans cultures. One reason for this may be the salivary buffering action which neutralises the yeastderived carboxylic acids that have rapidly accumulated during the $\log$ phase of yeast growth. It is known that acid production in yeast-salivary cultures peaks at the $\log$ phase of growth and declines or abates thereafter
$[17,23]$. An acidic $\mathrm{pH}$ is crucial for proteinase expression in Candida spp. The fact that the species with the most robust acidogenic potential (C. albicans) was able to induce a higher degree of proteinase expression and proteolytic activity than $C$. tropicalis and $C$. parapsilosis which are known to be less acidogenic, implies that the latter characteristic is a contributory factor in virulence.

The study of $C$. albicans Saps is complex, as their 


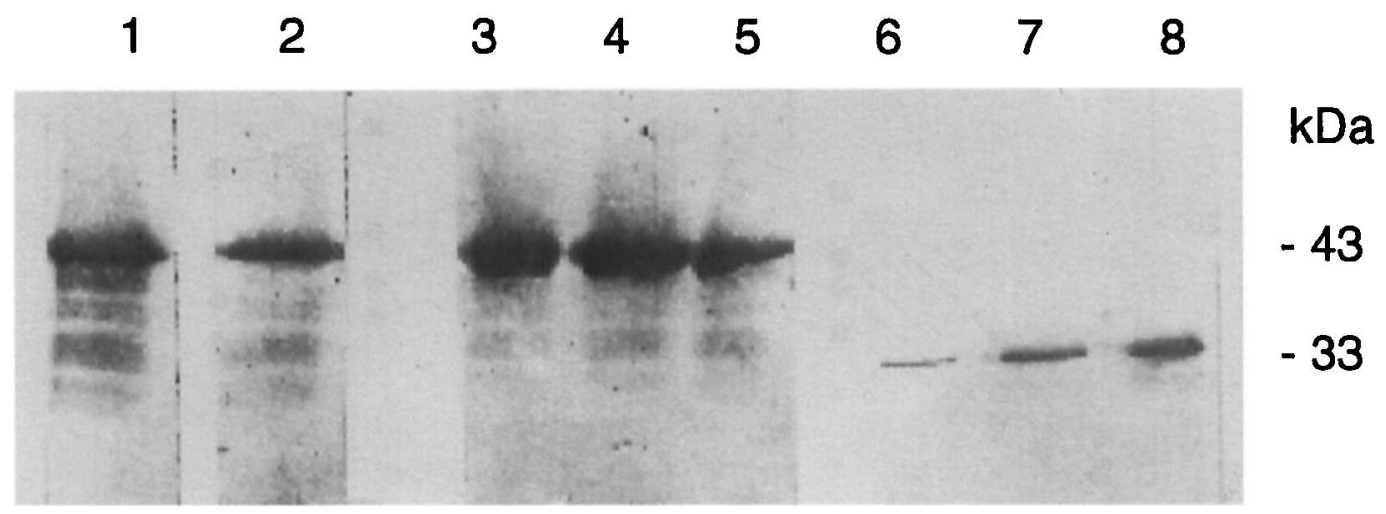

Fig. 5. Western blot of supernates from three Candida spp. cultured in human whole saliva and YCB-BSA medium. Lane 1, purified Sap; 2, saliva culture with $C$. albicans BM20617; 3, purified Sapt; 4, YCB-BSA medium with $C$. tropicalis 003T; 5, saliva culture with $C$. tropicalis 003T; 6, saliva culture with C. parapsilosis 154538(1); 7, YCBBSA medium with $C$. parapsilosis $154538(1) ; \mathbf{8}$, purified Sapp. The molecular size of both purified Sap and Sapt used in this study was $43 \mathrm{kDa}$, while that of Sapp was $33 \mathrm{kDa}$.

production is encoded by a multigene family with at least nine members responsible for the production of Sap1 - Sap9. Recent investigations with Sap-deficient mutants have indicated clearly that Sap2 is the most important member of the group [26]. Furthermore, Sap2 appears to be a prerequisite for candidal growth in media with protein as the sole nitrogen source (as in the current study), although Sap4, Sap5 and Sap6 play a subsidiary role in the induction of Sap2 [26]. The current results have, for the first time, confirmed the hypothesis of differential expression of Sap, Sapt and Sapp in whole saliva, by means of ELISA and Western blotting techniques. Although previous workers have calibrated Sap expression in whole saliva in semiquantitative terms [17], the antigenic and electrophoretic properties of the expressed Saps of Candida spp. have not been described hitherto.

Inter-species variations in Sap expression have also been demonstrated by the current data. In both the YCB-BSA medium and the saliva cultures, $C$. albicans tended to be more proteolytic than either $C$. tropicalis and $C$. parapsilosis. On the other hand, the proteolytic activity and the proteinase expression in the case of the latter two species were very similar. One reason for this could be the profuse growth of $C$. albicans in the test media as compared with non-albicans species, observed here as well as by others [17]. Despite this caveat, the results of the present study tend to confirm the recognised hierarchy of virulence in Candida spp. - as $C$. albicans is considered to be the most virulent compared with $C$. tropicalis and $C$. parapsilosis [27]. However, the latter two, together with $C$. albicans, are distinguishable from other Candida spp. in possessing aspartyl proteinases that are secreted extracellularly. Indeed, it is interesting to note that $C$. parapsilosis, first considered a harmless yeast (isolated from fruits and other inanimate material) is now regarded as an emerging pathogen capable of causing considerable mortality - especially in hospitalised and other immunocompromised patient groups [28].
When the maxima of proteinase activity and enzyme concentration were compared, (the latter in terms of the antigen level), there was a 12-h time lag between the peaks of these parameters. This phenomenon has also been reported by others [21] and may be due to the fact that ELISA measures the total amount of antigen present compared with spectrophotometric assessment, where only the active enzyme is detected.

It was noteworthy that, over the $72-\mathrm{h}$ period of incubation, total salivary protein concentration decreased at different rates. Similar findings have been reported previously by Samaranayake et al. [17] for both $C$. albicans and $C$. tropicalis in human whole saliva. The most likely explanation for this phenomenon is the differential rates of degradation of salivary proteins by the expressed candidal proteinases.

It is debatable whether the in-vitro conditions employed in this study prevail intra-orally and whether the Saps have a role in the pathogenesis of oral infection. Intraoral habitats with low $\mathrm{pH}$ values are found in sites protected from the flushing action of saliva, such as the upper denture fitting surface [29]. Furthermore, regular and prolonged intake of carbohydrate foods lowers the $\mathrm{pH}$ in denture plaque to $c$. $\mathrm{pH} 4-5[16,30]$, conducive to Sap activity. Furthermore, Darlington [31] has demonstrated that salivary glucose and sucrose concentrations may reach up to $500 \mathrm{mM}$, depending on the frequency and duration of intake of dietary carbohydrates. Also, a high carbohydrate intake is known to initiate or aggravate, or both, Candida-associated denture stomatitis $[32,33]$. Not only would such an environment stimulate Sap expression, but it may enhance the proliferation [34] and adhesion of $C$. albicans to palatal epithelial cells [35-37] and acrylic denture surfaces $[38,39]$. Recent work has shown that in addition to a primary enzymic role, various Saps may act singly or synergically to enhance the adhesiveness of $C$. albicans to human tissues [40], as well as cleaving mucosal immunoglobulins [6], thus facil- 
a
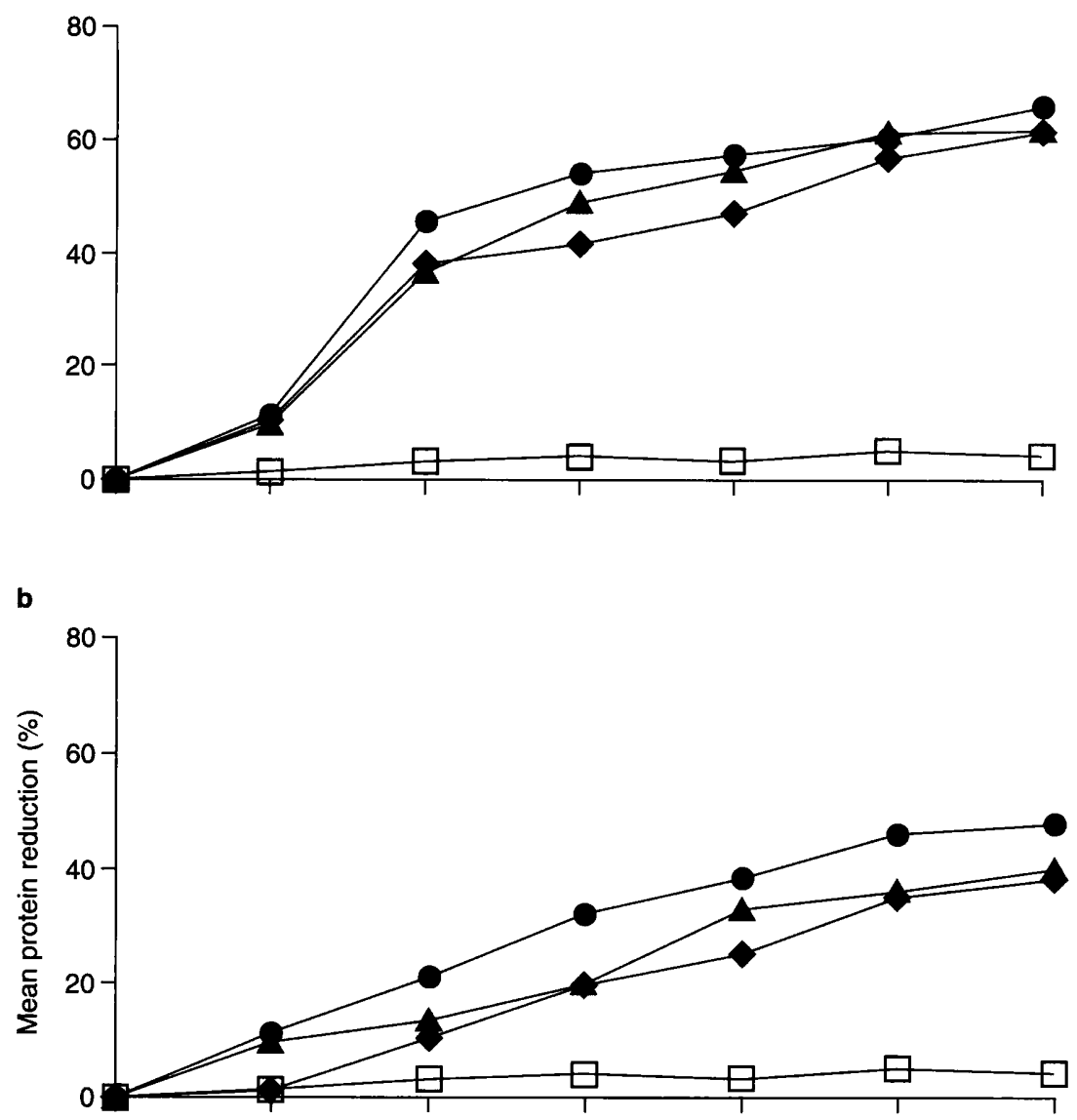

c

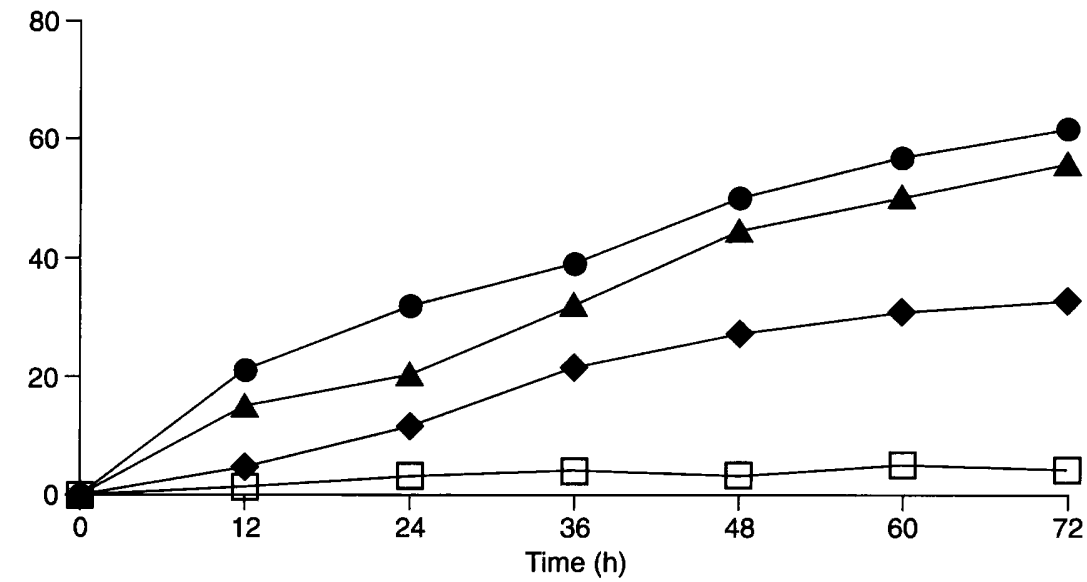

Fig. 6. Percentage reduction of salivary proteins induced by (a) C. albicans BM20617 (), BU1010 (A) and BS742

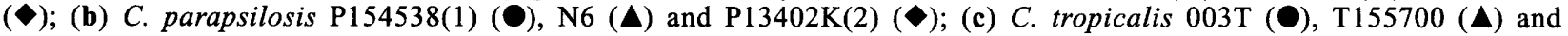
T155646 $(\diamond)$ during incubation for $72 \mathrm{~h}$ in human whole saliva and a Candida-free saliva control sample ( $\square$ ).

itating yeast colonisation. Taken together, these findings tend to support the theory that the Saps of Candida spp. could indeed contribute to the pathogenesis of Candida-associated denture stomatitis [5, 41], the most prevalent oral candidal infection in the West.

In conclusion, these results demonstrate that Candida spp. secrete aspartyl proteinases of broad substrate specificity with the ability to induce salivary proteo- lysis and possibly tissue damage. Furthermore, there are significant inter-species differences in Sap expression in whole saliva. However, further studies are needed to differentiate the proteinase iso-enzymes expressed by the yeasts, in biological fluids such as saliva and serum, and to elicit qualitative data on the specific, constituent proteins which are degraded. In addition, in-vivo experimentation, possibly in an animal model, is essential to confirm these findings. 


\section{References}

1. Staib F. Serum-proteins as nitrogen source for yeastlike fungi. Sabouraudia 1965; 4: 187-193.

2. Ruchel R, Uhlemann, Boning B. Secretion of acid proteinases by different species of the genus Candida. Zentralbl Bakteriol Microbiol Hyg [A] 1983; 255: 537-548.

3. Ruchel R. A variety of Candida proteinases and their possible targets of proteolytic attack in the host. Zentralbl Bakteriol Microbiol Hyg [A] 1984; 257: 266-274.

4. Odds FC. Candida albicans proteinase as a virulence factor in the pathogenesis of Candida infections. Zentralbl Bakteriol Microbiol Hyg [A] 1985; 260: 539-542.

5. Ogrydziak DM. Yeast extracellular proteases. Crit Rev Biotechnol 1993; 13: 1-55.

6. Ruechel $\mathrm{R}$. Virulence factors of Candida species. In: Samaranayake LP, MacFarlane TW (eds) Oral candidosis. London, Wright. 1990: 47-65.

7. Ghannoum M, Abu Elteen K. Correlative relationship between proteinase production, adherence and pathogenicity of various strains of Candida albicans. J Med Vet Mycol 1986; 24: 407-413.

8. Kwon-Chung KJ, Lehman JD, Good C, Magee PT. Genetic evidence for role of extracellular proteinase in virulence of Candida albicans. Infect Immun 1985; 49: 571-575.

9. Hube B, Sanglard D, Odds FC et al. Disruption of each of the secreted aspartyl proteinase genes $S A P 1, S A P 2$, and $S A P 3$ of Candida albicans attenuates virulence. Infect Immun 1997; 65: 3529-3538.

10. Wright RJ, Carne A, Hieber AD, Lamont IL, Emerson GW, Sullivan PA. A second gene for a secreted aspartate proteinase in Candida albicans. $J$ Bacteriol 1992; 174: 7848-7853.

11. Crandall M, Edwards JE. Segregation of proteinase-negative mutants from heterozygous Candida albicans. J Gen Microbiol 1987; 133: 2817-2824.

12. Monod M, Togni G, Hube B, Sanglard D. Mutiplicity of genes encoding secreted aspartic proteinases in Candida species. Mol Microbiol 1994; 13: 357-368.

13. Rüchel R, Böning B, Borg M. Characterization of a secretory proteinase of Candida parapsilosis and evidence for the absence of the enzyme during infection in vitro. Infect Immun 1986; 53: 411-419.

14. Tenovuo J, Lumikari $M$, Soukka $T$. Salivary lysozyme lactoferrin and peroxidases: antibacterial effects on cariogenic bacteria and clinical applications in preventive dentistry. Proc Finn Dent Soc 1991; 87: 197-208.

15. Germaine GR, Tellefson LM. Effect of $\mathrm{pH}$ and human saliva on protease production by Candida albicans. Infect Immun 1981; 31: 323-326.

16. Samaranayake LP, Geddes DAM, Weetman DA, MacFarlane TW. Growth and acid production of Candida albicans in carbohydrate supplemented media. Microbios 1983; 37: 105-115.

17. Samaranayake YH, MacFarlane TW, Samaranayake LP, Aitchison TC. The in vitro proteolytic and saccharolytic activity of Candida species in human saliva. Oral Microbiol Immunol 1994; 9: 229-235.

18. Mackenzie DWR. Serum tube identification of Candida albicans. $J$ Clin Pathol 1962; 15: 563-565.

19. White TC, Miyasaki SH, Agabian N. Three distinct secreted aspartic proteinases in Candida albicans. J Bacteriol 1993; 175: $6126-6133$

20. Daniels L, Richard SH, Phillips JA. Chemical analysis. In Gerhardt P, Murray RGE, Wood WA, Krieg NR (eds) Methods for general molecular bacteriology. Washington, DC, American Society for Microbiology. 1994: 512-554.

21. Angiolella L, De Bernardis F, Bromuro C, Modello F, Ceddia
T, Cassone A. The effect of antimycotics on secretory acid proteinase of Candida albicans. J Chemother 1990; 2: 55-61.

22. De Bernardis F, Agatensi L, Ross IK et al. Evidence for a role for secreted aspartate proteinases of Candida albicans in vulvovaginal candidiasis. $J$ Infect Dis 1990; 161: 1276-1283.

23. Samaranayake LP, Hughes A, MacFarlane TW. The proteolytic potential of Candida albicans in human saliva supplemented with glucose. J Med Microbiol 1984; 17: 13-22.

24. Ramachandran K, Walker TK. Glucose metabolism by Candida albicans. Biochim Biophys Acta 1957; 65: 20-24.

25. Shepherd MG, Sullivan PA. The production and growth characteristics of yeast and mycelial forms of Candida albicans in continuous culture. $J$ Gen Microbiol 1976; 93 361-370.

26. Sanglard D, Hube B, Monod M, Odds FC, Gow NAR. A triple deletion of the secreted aspartyl proteinase genes SAP4, SAP5, and SAPG of Candida albicans causes attenuated virulence. Infect Immun 1997; 65: 3539-3546.

27. Samaranayake LP. Oral candidosis: an old disease in new guises. Dent Update 1990; 17: 36-38.

28. Nguyen MH, Peacock JE, Morris AJ et al. The changing face of candidemia: emergence of non-Candida albicans species and antifungal resistance. Am $J$ Med 1996; 100: 617-623.

29. Zgraggen U, Graf H. pH-Veranderungen unter oberkiefervollprothesensso. [ $\mathrm{pH}$ changes underneath complete maxillary dentures] Schweiz Monatsschr Zahnheikd 1975; 85: 797-812.

30. Olsen I, Birkeland JM. Assessment of denture plaque $\mathrm{pH}$ in subjects with and without denture stomatitis. Scand $J$ Dent Res 1975; 83: 370-374.

31. Darlington W. Metabolism of sucrose by Streptococcus mutans (NCTC 10904) and its relevance to the oral environment. $\mathrm{PhD}$ thesis, University of Glasgow 1978.

32. Gentles JC, La Touche CJ. Yeasts as human and animal pathogens. In: Rose AH, Harrison JS (eds) The yeasts, vol 1: Biology of yeasts. London, Academic Press. 1969: 107-182.

33. Ritchie GM, Fletcher AM, Main DMG, Prophet AS. The etiology, exfoliative cytology, and treatment of denture stomatitis. J Prosthet Dent 1969; 22: 185-200.

34. Knight L, Fletcher J. Growth of Candida albicans in saliva stimulation by glucose associated with antibiotics, corticosteroids, and diabetes mellitus. $J$ Infect Dis 1971; 123 371-377.

35. Douglas LJ, Houston JG, McCourtie J. Adherence of Candida albicans to human buccal epithelial cells after growth on different carbon sources. FEMS Microbiol Lett 1981; 12: 241-243.

36. Samaranayake LP, MacFarlane TW. The adhesion of the yeast Candida albicans to epithelial cells of human origin in vitro. Arch Oral Biol 1981; 26: 815-820.

37. Samaranayake LP, MacFarlane TW. Factors affecting the invitro adherence of the fungal oral pathogen Candida albicans to epithelial cells of human organ. Arch Oral Biol 1982; 27: 869-873.

38. Samaranayake LP, MacFarlane TW. An in-vitro study of the adherence of Candida albicans to acrylic surfaces. Arch Oral Biol 1980; 25: 603-609.

39. McCourtie J, Douglas LJ. Relationship between cell surface composition of Candida albicans and adherence to acrylic after growth on different carbon sources. Infect Immun 1981; 32: $1234-1241$

40. Watts HJ, Cheah FSH, Hube B, Sanglard D, Gow NAR. Altered adherence in strains of Candida albicans harbouring null mutations in secreted aspartic proteinase genes. FEMS Microbiol Lett 1998; 159: 129-135.

41. Budtz-Jörgensen E. Candida-associated denture stomatitis and angular cheilitis. In: Samaranayake LP, MacFarlane TW (eds) Oral candidosis. London, Wright. 1990: 156-183. 